\title{
Compostos antioxidantes de jurubeba in natura e em conservas
}

O presente estudo teve como objetivo determinar os teores de clorofilas a e b, carotenoides totais, fenólicos totais, poder redutor e a inibição dos radicais ABTS e DPPH em frutos de jurubeba in natura e em conserva. O estudo foi dividido em duas etapas. Na primeira, frutos frescos foram avaliados segundo o estádio de maturação e o local de coleta. Na segunda etapa, conservas de jurubeba adquiridas no comércio local de Cáceres-MT foram avaliadas. O local de coleta não influenciou o conteúdo dos compostos bioativos avaliados, com exceção dos carotenoides totais. Da mesma forma, a atividade antioxidante foi pouco influenciada pelos locais de coleta. A maturação da jurubeba não teve influência sobre os antioxidantes avaliados. Entretanto, os frutos maduros apresentaram maior inibição do radical DPPH e maior poder redutor que os frutos imaturos. A conserva de jurubeba possui alto teor de compostos antioxidantes, comparável a alimentos de reconhecido potencial. Os resultados do presente estudo corroboram com as informações disponíveis na literatura, confirmando o potencial deste alimento como nutracêutico.

Palavras-chave: Solanum paniculatum; Carotenoides; Fenólicos; Alimento funcional.

\section{Antioxidant componds of fresh and pickled 'jurubeba'}

The presente study was aimed to determined the levels of chlorophylls a and b, total carotenoids, total polyphenols, reducing power and the inhibition of radicals ABTS and DPPH in fresh and pickled 'jurubeba'. The research was divided into two studies. In the first, fresh fruits were evaluated according to the maturity stage and place of collection. In the second study, pickled jurubeba purchased in the local commerce of Cáceres-MT were evaluated. The sites of collection did not influence the content of the bioactive compounds evaluated, with the exception of total carotenoids. The maturation of jurubeba had no influence on the antioxidants evaluated. However, ripe fruits showed greater inhibition of the DPPH radical and greater reducing power than immature fruits. The pickled jurubeba has a high content of antioxidant compounds, comparable to foods of recognized potential. The results of the present study corroborate the information available in the literature, confirming the potential of this food as a nutraceutical.

Keywords: Solanum paniculatum; Carotenoids; Phenolics; Functional food.

Topic: Uso de Recursos Naturais

Reviewed anonymously in the process of blind peer.
Received: 04/07/2021

Approved: $27 / 07 / 2021$
Claudia Virgínia de Andrade Gonzaga

Universidade do Estado de Mato Grosso, Brasil

http://lattes.cnpq.br/6878701472567194

http://orcid.org/0000-0003-1410-6036

claudiavirginiagonzaga@gmail.com

Renê Arnoux da Silva Campos (ib)

Universidade do Estado de Mato Grosso, Brasil

http://lattes.cnpq.br/1909312987145520

http://orcid.org/0000-0002-3736-2801

renecampos@unemat.br

José Advan Pereira Pedrosa Júnior (iD

Universidade do Estado de Mato Grosso, Brasil

http://lattes.cnpq.br/9388589798820536

http://orcid.org/0000-0002-3736-2801

junior.pedrosaluz@gmail.com

\author{
Mônica Bartira da Silva (iD \\ Universidade do Estado de Mato Grosso, Brasil \\ http://lattes.cnpq.br/1682086854972286 \\ http://orcid.org/0000-0002-7730-2213 \\ monica.bartira@gmail.com \\ Samuel Laudelino Silva \\ Universidade do Estado de Mato Grosso, Brasil \\ http://lattes.cnpq.br/1346491409078510 \\ http://orcid.org/0000-0002-6466-3984 \\ samuel@unemat.br
}

Referencing this:

GONZAGA, C. V. A.; CAMPOS, R. A. S.; PEDROSA JUNIOR, J. A. P.; SILVA, M. B.; SILVA, S. L.. Compostos antioxidantes de jurubeba in natura e em conservas. Revista Ibero Americana de Ciências Ambientais, v.12, n.7, p.465-474, 2021. DOI: http://doi.org/10.6008/CBPC21796858.2021 .007 .0040

DOI: 10.6008/CBPC2179-6858.2021.007.0040 


\section{INTRODUÇÃO}

A jurubeba (Solanum paniculatum L.) é uma hortaliça não convencional cujos frutos são consumidos principalmente após o cozimento, em conservas preparadas em vinagre e óleo. É também utilizada como medicinal, compondo xaropes e elixires indicados no tratamento de disfunções gástricas, bronquite e anemia (CORRÊA, 1978). Estudos demonstraram que a jurubeba possui atividade anti-inflamatória (RIOS et al., 2017), antiúlcera (VELA et al., 2002), antibacteriana (LOBO et al., 2010) e antiviral (VALADARES et al., 2010) da jurubeba, confirmando as indicações tradicionais.

Uma pesquisa sobre frutos nativos do Brasil ainda pouco estudados mostrou que a jurubeba possui alta atividade antioxidante, comparável a plantas de reconhecida atividade, como p.ex. morango (Fragaria sp.) e mirtilo (Vaccinium sect. Cyanococcus Rydb.) (GREGORIS et al., 2013). A jurubeba é rica em substâncias bioativas, incluindo clorofilas, carotenoides, taninos e flavonoides (SILVA et al., 2016; LOBO et al., 2010). De acordo com Gregoris et al. (2013), a atividade antioxidante da planta está relacionada ao alto conteúdo de fenólicos (GREGORIS et al., 2013; COSTA et al., 2014). As clorofilas e carotenoides são igualmente importantes para a jurubeba consumida em conserva, pois indicam a qualidade deste alimento, podendo variar em razão do tempo de cozimento e dos ingredientes utilizados durante o preparo (SILVA et al., 2016).

Por ser rústica, a espécie é frequentemente cultivada em quintais, áreas urbanas em pousio ou em pequenas propriedades rurais, não requerendo maiores cuidados no cultivo. São, portanto, produzidas em ambientes heterogêneos, o que pode influenciar nos teores de antioxidantes. Sabe-se que os fatores bióticos, abióticos e as práticas agrícolas empregadas durante o cultivo de plantas hortícolas podem interferir nos teores de compostos antioxidantes (ASAMI et al., 2003). Esses fatores modulam os mecanismos de defesa vegetal, disparando diversos processos bioquímicos complexos (LøVDAL et al., 2010). Desta forma, torna-se importante avaliar o conteúdo de compostos antioxidantes em frutos oriundos de diferentes locais de coleta.

Além disso, a variação nos teores de antioxidantes da jurubeba durante a maturação dos frutos não está clara. Nas solanáceas, a maturação pode tanto aumentar como diminuir o teor de antioxidantes nos frutos (ABBE et al., 2019; OUERGHEMMI et al., 2017).

Por ser uma hortaliça não convencional, estudos sobre a composição química da jurubeba contribuem com a valorização cultura alimentar regional, uma maior oferta de alimentos ao longo do ano, a produção de alimentos em áreas improdutivas e o aumento na renda para pequenos agricultores (RANIERI, 2017). Dessa forma, o objetivo do presente estudo foi determinar os teores de clorofilas, carotenoides, fenólicos e a atividade antioxidante em frutos de jurubeba in natura em diferentes estádios de maturação, produzidos em diferentes locais do município de Cáceres-MT e também avaliar conservas de jurubeba comercializadas no município.

\section{MATERIAIS E MÉTODOS}

\section{Local do estudo e delineamento experimental}

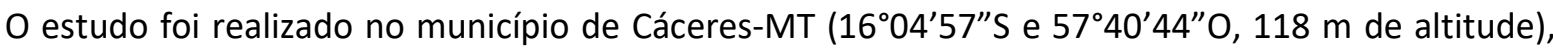


localizado na microrregião do Alto Pantanal. O município apresenta clima Tropical subúmido (Aw), com seca durante o outono/inverno e chuva na primavera/verão, médias anuais de temperatura de $24,8^{\circ} \mathrm{C}$, precipitação de 1202 mm e evapotranspiração potencial de 1612 mm (SOUZA et al., 2013).

A presente pesquisa foi dividida em dois estudos. O primeiro avaliou a jurubeba in natura segundo o estádio de maturação dos frutos coletados em diferentes locais de Cáceres. O segundo estudo avaliou oito conservas adquiridas no comércio local do município. A pesquisa foi cadastrada no Sistema Nacional de Gestão do Patrimônio Genético e do Conhecimento Tradicional Associado (SisGen) com o no AOCF1EA.

Para a análise da jurubeba in natura, amostras de $500 \mathrm{~g}$ foram colhidas aleatoriamente em seis locais de coleta em diferentes locais do município: Vila Irene, Cavalhada, Espirito Santo, DNER, Aterro e Morraria, sendo os dois últimos locais pertencentes à zona rural de Cáceres. Em cada local de coleta foram avaliadas três plantas, sendo cada matriz considerada uma repetição experimental. Em cada planta, os frutos foram classificados visualmente em três estádios de maturação: estádio inicial, frutos de tamanho pequeno e \pm 500 mg de massa; estádio intermediário, frutos de tamanho médio com $\pm 1 \mathrm{~g}$ de massa; e estádio avançado, frutos de tamanho grande com $\pm 1,5 \mathrm{~g}$ de massa.

Em laboratório, os frutos foram selecionados e limpos. Depois, foram macerados em nitrogênio líquido e armazenados em refrigerador a $-20^{\circ} \mathrm{C}$ até o momento das análises. $\mathrm{O}$ experimento seguiu um delineamento experimental em parcelas subdivididas (6x3) com seis locais de coleta (parcela), três estádios de desenvolvimento dos frutos (subparcela) e três repetições, totalizando 54 parcelas experimentais.

Para as análises das conservas, oito amostras foram adquiridas no comércio local de Cáceres, oriundas de diferentes comerciantes. O tempo de cozimento e ingredientes utilizados no preparo das conservas avaliadas são descritos a seguir. Conserva 1: 5 min cozimento, vinagre de maça e sal; Conserva 2: 5 min cozimento, vinagre de vinho branco, orégano e alho; Conserva 3: 5 min de cozimento, vinagre de vinho branco, sal, orégano e alho; Conserva 4: 5 min de cozimento, vinagre comum e sal; Conserva 5: 5 min cozimento, vinagre comum e sal; Conserva 6: 5 min cozimento, vinagre de vinho branco, sal, gengibre e alho; Conserva 7: vinagre de vinho branco, sal, pimenta do reino em grãos e alho; Conserva 8: 15 min de cozimento, vinagre comum e sal.

Em laboratório, as conservas foram mantidas em refrigerador a $\pm 5^{\circ} \mathrm{C}$ até o momento das análises bioquímicas. $O$ experimento seguiu um delineamento experimental inteiramente casualizado, com oito tratamentos e três triplicatas, totalizando 24 parcelas experimentais.

\section{Determinação da clorofila a (Cla), clorofila b (Clb) e carotenoides totais (Crt)}

Os teores de $\mathrm{Cl} a, \mathrm{Cl} b$ e $\mathrm{Crt}$ foram determinados segundo procedimentos descritos por Wellburn (1994). Amostras frescas foram extraídas em dimetilsulfóxido (DMSO). Os resultados foram expressos em

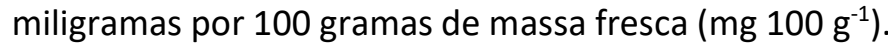

\section{Preparação do extrato para as análises de Ft, ABTS, DPPH e FRAP}

Amostras de jurubeba foram misturadas em etanol PA. A mistura foi agitada em vórtex por 1 min, 
sonicada por $3 \mathrm{~min}$ e centrifugada por $15 \mathrm{~min}$ a $11000 \times \mathrm{g}$. O sobrenadante foi coletado e armazenado em freezer a $-20^{\circ} \mathrm{C}$. A extração foi repetida com metanol PA e metanol acidificado ( $1 \% \mathrm{HCl}$ em metanol PA). Os sobrenadantes foram combinados e permaneceram armazenados até o momento das análises.

\section{Determinação de fenólicos totais (Ft)}

O teor de Ft foi determinado segundo procedimentos descritos por Singleton e Rossi (1965). Uma curva de ácido gálico (0-50 $\mu \mathrm{g})$ foi utilizada para calibrar a análise $\left(R^{2}=0,995\right)$. Os resultados foram expressos em miligramas de ácido gálico equivalente por 100 gramas de massa fresca (mg GAE $100 \mathrm{~g}^{-1}$ ).

\section{Inibição do radical 2,2'-Azino-bis(3-ethylbenzothiazoline-6-sulfonic acid) ABTS}

A inibição do radical ABTS foi procedida segundo procedimentos descritos por RE et al. (1999). A inibição do radical ABTS foi expressa em porcentagem. Uma curva de trolox (0-500 $\mu \mathrm{g})$ foi utilizada para calibrar a análise $\left(R^{2}=0,996\right)$. Os resultados foram expressos em gramas de trolox equivalente por 100 gramas de fruto $\left(\mathrm{g}\right.$ TE $\left.100 \mathrm{~g}^{-1}\right)$.

\section{Inibição do radical 2,2-difenil-1-picrilhidrazil (DPPH)}

A inibição do radical DPPH foi determinada segundo procedimentos descritos por (WILLIAMS et al., 1995). A inibição do radical DPPH foi expressa em porcentagem. Uma curva de trolox (0-25 $\mu \mathrm{g}$ ) foi utilizada para calibrar a análise $\left(R^{2}=0,996\right)$. Os resultados expressos em $\mathrm{mg}$ de trolox equivalente por $100 \mathrm{~g}$ de massa fresca (mg TE $\left.100 \mathrm{~g}^{-1}\right)$.

\section{Poder redutor (FRAP)}

O FRAP dos extratos de frutos de jurubeba foi determinado segundo procedimentos descritos por Benzie e Strain. Uma curva de sulfato de ferro $(0-120 \mu \mathrm{g})$ foi utilizada para calibrar a análise $\left(R^{2}=0,991\right)$. Os resultados foram expressos em milimol de ferro reduzido por $\mathrm{kg}$ de massa seca $\left(\mathrm{mmol} \mathrm{Fe}{ }^{2+} \mathrm{kg}^{-1}\right)$.

\section{Análise dos resultados}

Todas as análises foram realizadas em triplicata e os resultados foram expressos como médias. As diferenças entre as amostras foram determinadas por meio da análise de variância one-way (ANOVA). O teste post hoc de Tukey (HSD) foi utilizado para comparar os grupos e determinar se as diferenças foram significativas $(P<0.05)$. As análises estatísticas foram realizadas utilizando o software Sisvar 5.7 Build 91 (DEX-UFLA, Brasil).

\section{RESULTADOS}

Os teores de clorofila $a$, clorofila $b$ e fenólicos totais foram semelhantes entre os diferentes locais de produção avaliados (Tabela 1). Porém, uma leve variação foi observada no teor de carotenoides totais. Quanto à maturidade dos frutos de jurubeba, os teores de clorofila $a$, clorofila $b$, carotenoides totais e 
fenólicos totais foram semelhantes entre os estádios maturação avaliados.

Tabela 1: Teores de clorofila $a(\mathrm{Cla})$, clorofila $b(\mathrm{Cl} b)$, carotenoides totais ( $\mathrm{Crt}$ ) e fenólicos totais ( $\mathrm{Ft}$ ) em frutos de jurubeba in natura produzidos em diferentes locais e em função do tamanho do fruto.

\begin{tabular}{|c|c|c|c|c|}
\hline & $\begin{array}{l}\text { Cla } \\
\left(\mathrm{mg} 100 \mathrm{~g}^{-1}\right)\end{array}$ & $\begin{array}{l}\mathrm{Clb} \\
\left(\mathrm{mg} 100 \mathrm{~g}^{-1}\right)\end{array}$ & $\begin{array}{l}\text { Crt } \\
\left(\mathrm{mg} 100 \mathrm{~g}^{-1}\right)\end{array}$ & $\begin{array}{l}\text { Ft } \\
\left(\mathrm{mg} \mathrm{GAE} 100 \mathrm{~g}^{-1}\right)\end{array}$ \\
\hline \multicolumn{5}{|c|}{ Local de produção } \\
\hline Vila Irene $z$ & $6,51 a^{y}$ & $4,10 a$ & $2,48 a b$ & 372,8 a \\
\hline Cavalhada & 5,16 a & $3,61 \mathrm{a}$ & $1,84 \mathrm{~b}$ & 278,5 a \\
\hline Espírito Santo & $5,74 a$ & $3,78 \mathrm{a}$ & $2,15 a b$ & 299,3 a \\
\hline DNER & $5,36 a$ & $3,73 \mathrm{a}$ & $2,21 a b$ & 321,7 a \\
\hline Aterro & $6,86 a$ & $4,82 \mathrm{a}$ & $2,92 \mathrm{a}$ & 150,6 a \\
\hline Morraria & $5,65 a$ & $3,73 \mathrm{a}$ & $2,16 a b$ & 199,6 a \\
\hline DMS & 2,23 & 1,52 & 1,01 & 192,5 \\
\hline $\mathrm{CV} \%$ & 20,2 & 20,5 & 23,6 & 28,5 \\
\hline \multicolumn{5}{|c|}{ Tamanho do fruto } \\
\hline Pequeno $^{x}$ & $5,71 a^{y}$ & $3,98 \mathrm{a}$ & $2,10 a$ & 256,7 a \\
\hline Médio & $5,64 a$ & $4,03 a$ & $2,30 \mathrm{a}$ & $263,0 \mathrm{a}$ \\
\hline Grande & $6,07 a$ & $3,79 a$ & $2,37 a$ & $311,7 \mathrm{a}$ \\
\hline DMS & 0,62 & 0,54 & 0,31 & 87,2 \\
\hline CV\% & 11,1 & 14,3 & 14,5 & 17,3 \\
\hline
\end{tabular}

${ }^{2}$ Valores representam a média das três classes de tamanho de fruto.

${ }^{y}$ Médias nas colunas seguidas da mesma letra não diferem entre si a $P \leq 0,05$ de acordo com o teste de Tukey.

${ }^{x}$ Valores representam a média dos seis locais de coleta.

Uma leve diferença na inibição do radical ABTS foi observada entre os locais de produção (Tabela 2). Entretanto, a inibição do radical DPPH e o poder redutor (FRAP) foram similares entre os tratamentos. Quanto à maturidade fruto, frutos em estádio avançado apresentaram maior atividade antioxidante frente ao radical DPPH e maior poder redutor que os frutos em estádio inicial de maturação.

Tabela 2: Inibição dos radicais 2,2-azinobis 3-etilbenzotiazolina-6-ácido sulfônico (ABTS), 2,2-difenil-1-picrilhidrazil (DPPH) e poder redutor (FRAP) em frutos de jurubeba in natura em frutos de jurubeba in natura produzidos em diferentes locais e em função do tamanho do fruto.

\begin{tabular}{|c|c|c|c|}
\hline & $\begin{array}{l}\text { ABTS }{ }^{c} \\
\left(g_{\left.\text {TE } 100 g^{-1}\right)}\right.\end{array}$ & $\begin{array}{l}\text { DPPH } \\
\left(\mathrm{mg} \mathrm{TE} 100 \mathrm{~g}^{-1}\right)\end{array}$ & $\begin{array}{l}\text { FRAP } \\
\left(\mathrm{mmol} \mathrm{Fe}{ }^{2+} \mathrm{kg}^{-1}\right)\end{array}$ \\
\hline \multicolumn{4}{|l|}{ Local de coleta } \\
\hline Vila Irene ${ }^{z}$ & $4,50 a^{y}$ & $144,4 \mathrm{a}$ & $21,5 \mathrm{a}$ \\
\hline Cavalhada & $2,35 a b$ & 140,7 a & $12,2 \mathrm{a}$ \\
\hline Espírito Santo & $3,56 a b$ & $129,4 \mathrm{a}$ & $21,2 \mathrm{a}$ \\
\hline DNER & $2,74 a b$ & 140,8 a & $18,5 \mathrm{a}$ \\
\hline Aterro & $2,59 a b$ & $135,0 \mathrm{a}$ & $10,4 \mathrm{a}$ \\
\hline Morraria & $2,08 \mathrm{~b}$ & 133,8 a & $10,2 \mathrm{a}$ \\
\hline DMS & 2,20 & 22,5 & 18,3 \\
\hline CV\% & 13,2 & 8,06 & 25,1 \\
\hline \multicolumn{4}{|c|}{ Tamanho do fruto } \\
\hline Pequeno $^{x}$ & $2,49 a^{y}$ & $134,1 \mathrm{~b}$ & $11,3 \mathrm{~b}$ \\
\hline Médio & $3,30 \mathrm{a}$ & $134,4 \mathrm{~b}$ & $16,8 a b$ \\
\hline Grande & $3,43 \mathrm{a}$ & 143,8 a & $18,9 \mathrm{a}$ \\
\hline DMS & 1,03 & 5,98 & 5,03 \\
\hline CV\% & 13,3 & 4,30 & 6,16 \\
\hline
\end{tabular}

${ }^{z}$ Valores representam a média das três classes de tamanho de fruto.

${ }^{y}$ Médias nas colunas seguidas da mesma letra não diferem entre si a $P \leq 0,05$ de acordo com o teste de Tukey.

${ }^{x}$ Valores representam a média dos seis locais de coleta.

Os teores de clorofila $a$, clorofila $b$ e carotenoides totais apresentaram uma ligeira variação entre os diferentes tipos de conservas avaliadas, ao contrário do conteúdo de fenólicos totais, que não variou (Tabela 3). A Conserva 8, em que os frutos foram cozidos em água por 15 min e preparada com a própria água do cozimento, vinagre comum e sal apresentou a maior atividade antioxidante frente os radicais ABTS e DPPH e 
também o maior poder redutor. Nesta conserva, a inibição dos radicais ABTS e DPPH foi duas vezes maior que a média das demais conservas. O mesmo ocorreu com o poder redutor, sendo registrada uma atividade $120 \%$ maior que a média das demais conservas.

Tabela 3: Teores de clorofila a $(\mathrm{Cla})$, clorofila b $(\mathrm{Cl} b)$, carotenoides totais ( $\mathrm{Crt}$ ) e fenólicos totais (Ft) em conservas de jurubeba.

\begin{tabular}{|c|c|c|c|c|}
\hline & $\begin{array}{l}\text { Cla } \\
\left(\mathrm{mg} \mathrm{100g-1}^{-1}\right)\end{array}$ & 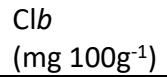 & 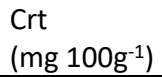 & $\begin{array}{l}\mathrm{Ft} \\
\left(\mathrm{mg} \mathrm{GAE} 100 \mathrm{~g}^{-1}\right)\end{array}$ \\
\hline \multicolumn{5}{|c|}{ Conserva } \\
\hline $1^{z}$ & $1,17 a b^{y}$ & $0,32 b$ & $0,53 b$ & 177,9 a \\
\hline 2 & $1,14 \mathrm{~b}$ & $0,26 b$ & $0,53 b$ & $174,3 \mathrm{a}$ \\
\hline 3 & 1,44 a & $0,32 b$ & $0,47 \mathrm{bc}$ & $184,4 \mathrm{a}$ \\
\hline 4 & $0,75 \mathrm{c}$ & 0,58 a & $0,70 \mathrm{a}$ & $170,7 \mathrm{a}$ \\
\hline 5 & $0,91 \mathrm{bc}$ & $0,29 \mathrm{~b}$ & $0,44 \mathrm{~cd}$ & $181,2 \mathrm{a}$ \\
\hline 6 & $1,04 \mathrm{~b}$ & $0,27 \mathrm{~b}$ & $0,38 d$ & $166,2 \mathrm{a}$ \\
\hline 7 & $1,07 \mathrm{~b}$ & $0,31 b$ & $0,52 b$ & $194,3 \mathrm{a}$ \\
\hline 8 & $1,05 b$ & $0,27 b$ & $0,45 \mathrm{c}$ & 196,6 a \\
\hline DMS & 0,27 & 0,10 & 0,06 & 32,9 \\
\hline CV\% & 9,19 & 10,7 & 11,8 & 6,31 \\
\hline
\end{tabular}

${ }^{z}$ Valores representam a média de três avaliações.

${ }^{y}$ Médias nas colunas seguidas da mesma letra não diferem entre si a $P \leq 0,05$ de acordo com o teste de Tukey.

Tabela 4: Inibição dos radicais 2,2-azinobis 3-etilbenzotiazolina-6-ácido sulfônico (ABTS), 2,2-difenil-1-picrilhidrazil (DPPH) e poder redutor (FRAP) em conservas de jurubeba.

\begin{tabular}{|c|c|c|c|}
\hline & 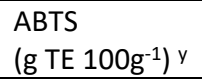 & 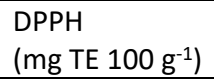 & $\begin{array}{l}\text { FRAP } \\
\left(\mathrm{mmol} \mathrm{Fe}{ }^{2+} \mathrm{kg}^{-1}\right)\end{array}$ \\
\hline \multicolumn{4}{|c|}{ Conserva } \\
\hline $1^{z}$ & 12,6 cde $^{y}$ & $412,3 \mathrm{~b}$ & $178,4 \mathrm{~b}$ \\
\hline 2 & $12,7 \mathrm{cde}$ & $395,3 \mathrm{~b}$ & $183,1 \mathrm{~b}$ \\
\hline 3 & $13,6 \mathrm{~cd}$ & $415,4 b$ & $179,1 \mathrm{~b}$ \\
\hline 4 & $11,3 \mathrm{de}$ & $465,2 \mathrm{~b}$ & $182,3 \mathrm{~b}$ \\
\hline 5 & $16,2 \mathrm{~b}$ & $480,3 \mathrm{~b}$ & $185,1 \mathrm{~b}$ \\
\hline 6 & $10,6 \mathrm{e}$ & $382,3 \mathrm{~b}$ & $166,4 \mathrm{~b}$ \\
\hline 7 & $14,0 \mathrm{bc}$ & 504,7 b & $189,4 a b$ \\
\hline 8 & $25,3 \mathrm{a}$ & 1115,3 a & 218,2 a \\
\hline DMS & 2,30 & 129,1 & 28,8 \\
\hline CV\% & 6,15 & 8,76 & 5,51 \\
\hline
\end{tabular}

${ }^{z}$ Valores representam a média de três avaliações.

${ }^{y}$ Médias nas colunas seguidas da mesma letra não diferem entre si a $P \leq 0,05$ de acordo com o teste de Tukey.

Apesar das conservas de jurubeba terem apresentado apenas uma pequena parcela do conteúdo de bioativos presentes nos frutos in natura, a atividade antioxidante das conservas mostrou-se muito superior. Por exemplo, o conteúdo de clorofila $a$, clorofila $b$ e carotenoides totais nas conservas de jurubeba foi $85 \%$ menor, em média, que o conteúdo destes pigmentos nos frutos in natura. Da mesma forma, o teor de fenólicos totais nas conservas foi 33\% menor que nos frutos in natura. Entretanto, a capacidade de inibição dos radicais ABTS e DPPH das conservas de jurubeba foi cinco vezes maior que nos frutos in natura. Quanto ao poder redutor, este foi 12 vezes maior nas conservas, em média.

\section{DISCUSSÃO}

No presente estudo, os conteúdos de clorofila $a$, clorofila $b$ e carotenoides totais nos frutos de jurubeba in natura (Tabela 1) foram semelhantes aos relatados por Silva et al. (2016). De acordo com os

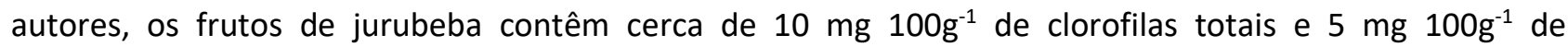
carotenoides totais. Entretanto, os mesmos autores relataram conteúdo de fenólicos totais (100 mg GAE 
$100 \mathrm{~g}^{-1}$ ) inferior aos resultados observados no presente estudo, que variou de 150 a $372 \mathrm{mg}$ GAE $100 \mathrm{~g}^{-1}$.

Os compostos fenólicos são substâncias comuns em frutas e hortaliças, havendo mais de oito mil compostos fenólicos já identificados no reino vegetal, muitos deles com ação protetora comprovada para a saúde humana (LIMA et al., 2014). As plantas sintetizam compostos fenólicos em resposta às pressões ecológicas tais como o ataque de patógenos e insetos, além de fatores ligados ao ambiente de cultivo como disponibilidade de nutrientes, temperatura, radiação UV (LøVDAL et al., 2010). Plantas cultivadas em sistemas sustentáveis ou orgânicos apresentam maior teor de compostos fenólicos que plantas conduzidas em sistema convencional (ASAMI et al., 2003). Provavelmente, estas diferenças no conteúdo de fenólicos observadas entre os estudos podem ser atribuídas às diferenças entre os ambientes de cultivo.

No presente estudo, apenas o conteúdo de carotenoides totais variou em razão do local de produção (Tabela 1), havendo pequenas diferenças entre os seis grupos de plantas. O mesmo ocorreu com a inibição do radical ABTS (Tabela 2). Entretanto, os resultados superiores de carotenoides totais não coincidiram com uma maior inibição do radical ABTS, indicando que outras substâncias presentes na jurubeba podem estar influenciando os resultados.

De maneira geral, os teores de clorofila $a$, clorofila $b$, fenólicos totais, assim como a inibição do radical DPPH e o poder redutor de jurubeba não diferiram entre os seis locais de coleta (Tabelas 1 e 2), indicando estabilidade na produção dos compostos bioativos avaliados e na atividade antioxidante em relação ao ambiente de produção. Dessa forma, podemos afirmar que o local de coleta não influencia o conteúdo dos compostos bioativos avaliados, com exceção dos carotenoides totais. Da mesma forma, a atividade antioxidante nos frutos de jurubeba é pouco influenciada pelos locais de coleta. Estes resultados são importantes para os produtores de jurubeba, pois indicam que a possibilidade de ampliar o processamento da jurubeba, criando uma cadeia produtiva com um produto local de qualidade padronizada.

No presente estudo, o efeito da maturação dos frutos de jurubeba sobre os teores de compostos antioxidantes também foi avaliado. Os teores de clorofila $a$, clorofila $b$, carotenoides totais e fenólicos totais foram similares entre frutos de diferentes estádios de maturação (Tabela 1). Entretanto, a inibição do radical DPPH e o poder redutor foram superiores nos frutos mais maduros, ou seja, a atividade antioxidante aumentou em razão da maturidade dos frutos. Estes resultados são comparáveis aos relatados em Solanum sodomeun L.. Na espécie, a maturação dos frutos causa aumento expressivo na inibição do radical DPPH, sendo fortemente correlacionada com o aumento nos teores dos ácidos gentísico e gálico (OUERGHEMMI et al., 2017). Entretanto, o estádio de maturação dos frutos não afeta o poder redutor dos frutos de $S$. sodomeum. Segundo os autores, estes resultados podem ser explicados pela ausência de moléculas redutoras nos extratos.

De maneira geral, os teores de carotenoides e compostos fenólicos nos frutos tendem a aumentar com a maturação dos tecidos e como consequência há um aumento na atividade antioxidante (LEE et al., 2018). Curiosamente, no presente estudo os teores de clorofila $a$, clorofila $b$, carotenoides totais e fenólicos totais permaneceram inalterados nos diferentes estádios de maturação avaliados, embora um aumento expressivo na inibição do radical DPPH e no poder redutor tenham sido observados em frutos em estádio 
avançado de maturação. Desta forma, podemos afirmar que a maturação da jurubeba não tem influência sobre os conteúdos de compostos bioativos avaliados. Entretanto, os frutos maduros apresentam maior atividade antioxidante frente ao radical DPPH e maior poder redutor que os frutos imaturos. Estes resultados são importantes para a cultura da jurubeba, pois a maturação dos frutos na espécie é desuniforme. Com base nos resultados deste estudo, produtores e consumidores poderão selecionar a jurubeba de sua preferência sem que haja diferenças nas propriedades funcionais em razão do amadurecimento dos frutos.

Além de avaliar o teor de compostos antioxidantes na jurubeba in natura, o presente estudo também buscou quantifica-los em conservas comercializadas no município de Cáceres-MT. Os teores de clorofilas e carotenoides nas conservas avaliadas no presente estudo foram diferentes dos relatados por Silva et al.

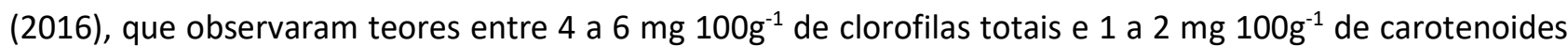
totais. Ainda segundo os autores, a perda destes bioativos provocada pelo cozimento é de cerca de $50 \%$. No presente estudo esta perda foi de $85 \%$, em média.

Durante o processamento térmico dos alimentos vegetais, a principal via de degradação das clorofilas é a substituição do magnésio por dois átomos de hidrogênio, conhecido como feofitinização. As feofitinas possuem coloração verde-oliva e são hidrolisáveis, resultando na liberação de fitol, um feoforbídeo hidrossolúvel (MARQUEZ, 2003). Na jurubeba, os conservantes utilizados no preparo das conservas têm maior influência no teor de clorofilas que o tempo de cozimento (SILVA et al., 2016). Segundo os mesmos autores, conservas que contém óleo de soja em sua composição possuem maior teor de clorofilas e carotenoides que conservas preparadas apenas com vinagre. Os resultados do presente estudo confirmaram em parte esta constatação: a conserva contendo óleo de soja (Conserva 4) apresentou o maior teor de clorofila $b$ e carotenoides totais, enquanto o teor de clorofila $a$ foi inferior aos teores observados nas conservas preparadas com vinagre, p.ex. Conserva 1 e Conserva 3 (Tabela 3).

Em relação ao conteúdo de fenólicos totais nas conservas de jurubeba, os resultados do presente estudo são similares aos relatados por Silva et al. (2016). Porém, houve diminuição de cerca de $30 \%$ nos teores destes compostos em relação aos frutos in natura. Silva et al. (2016), ao contrário, observaram aumento de cerca de $50 \%$ após o processamento. A diminuição no teor de fenólicos nos frutos de jurubeba após o cozimento observada no presente estudo foi similar à relatada em Solanum anguivi Lam. (ABBE et al., 2019).

No presente estudo, a Conserva 8 apresentou resultado superior em relação às demais conservas analisadas. Este resultado pode ser atribuído ao maior tempo de cocção utilizado no preparo desta conserva - $15 \mathrm{~min}$, enquanto as demais conservas foram cozidas em água por apenas $5 \mathrm{~min}$. $\mathrm{O}$ tratamento térmico aumenta o potencial antioxidante da jurubeba, sendo superior após 30 min de fervura (SILVA et al. 2016). Ainda de acordo com os autores, este efeito deve ser devido à liberação de compostos antioxidantes da matriz do fruto com o aumento da temperatura.

Em relação à atividade antioxidante das conservas de jurubeba, a tendência de aumento na inibição do radical DPPH após o processamento dos frutos observada no presente estudo foi similar à relatada por Silva et al. (2016). Porém, não é possível uma comparação precisa entre resultados porque no referido estudo 
a inibição do radical DPPH não foi expressa com base na massa fresca dos frutos.

Quanto ao efeito das conservas de jurubeba na inibição do radical ABTS e do poder redutor dos extratos, os resultados do presente estudo são os primeiros relatados na literatura para a jurubeba. Os resultados da inibição do radical ABTS das conservas de jurubeba $\left(15 \mathrm{mmol} \mathrm{TE} \mathrm{kg}^{-1}\right)$ são comparáveis à azeitona preta (Olea europaea L.) (PELLEGRINI et al., 2003). Entretanto, o poder redutor das conservas de jurubeba do presente estudo foi três vezes maior que o poder redutor relatado para a azeitona preta (40 $\left.\mathrm{mmol} \mathrm{Fe} \mathrm{kg}^{-1}\right)$. Desta forma, mais estudos são necessários sobre o poder redutor das conservas de jurubeba.

Como dito anteriormente, por meio de resultados obtidos em diferentes ensaios bioquímicos foi constatado que a jurubeba apresenta alto potencial antioxidante, sugerindo estudos adicionais sobre as propriedades nutracêuticas deste alimento (GREGORIS et al., 2013). Segundo os mesmos autores, as propriedades antioxidantes da jurubeba são devido ao alto conteúdo de fenólicos. Os resultados do presente estudo corroboram com os resultados disponíveis na literatura sobre a jurubeba, confirmando o alto potencial antioxidante dos frutos da espécie sua utilização como alimento nutracêutico.

\section{CONCLUSÕES}

O local de coleta não tem influência o conteúdo dos compostos bioativos avaliados nos frutos in natura, com exceção dos carotenoides totais. A maturação dos frutos não afeta os teores dos compostos bioativos avaliados. Entretanto, frutos em estádio avançado de maturação apresentam maior atividade antioxidante frente ao radical DPPH e maior poder redutor (FRAP) que frutos pequenos. As conservas de jurubeba possuem apenas uma pequena fração do conteúdo de bioativos presentes nos frutos in natura. Entretanto, a atividade antioxidante das conservas é muito superior. Portanto, a jurubeba quando consumida em conserva é um alimento/condimento rico em compostos antioxidantes.

\section{REFERÊNCIAS}

ABBE, C. Y.; ABOA, N.; AHI, P. A.. Antioxidant content in Solanum anguivi Lam. berries as affected by cooking at different stages of ripening. Asian Food Science Journal, v.13, n.2, p.1-10, 2019. DOI: http://doi.org/10.9734/afsj/2019/v13i230102

ASAMI, D. K.; HONG, Y. J.; BARRETT, D. M.; MITCHELL, A. E.. Comparison of the total phenolic and ascorbic acid content of freeze-dried and air-dried marionberry, strawberry, and corn grown using conventional, organic, and sustainable agricultural practices. Journal of Agricultural and Food Chemistry, v.51, n.5, p.1237-1241, 2003. DOI: http://doi.org/10.1021/jf020635c

CORRÊA, M. P.. Dicionário das plantas úteis do Brasil e das plantas exóticas cultivadas. Rio de Janeiro: Imprensa Nacional, 1978

COSTA, M. R. M.; SOUZA, P. H. S.; SILLVA, J. F.; FERNANDESPEDROSA, M. F.; PEREIRA, M. S. V.; LIMA, K. C..

Phytochemical screening and antibacterial activity of Solanum paniculatum Linn. against planktonic oral bacteria. African Journal of Microbiology Research, v.8, n.10, p.10011005, 2014. DOI: http://doi.org/10.5897/ajmr2013.6274
GREGORIS, E.; LIMA, G. P. P.; FABRIS, S.; BERTELLE, M.; SICARI, M.; STEVANATO, R.. Antioxidant properties of brazilian tropical fruits by correlation between different assays. BioMed Research International, v.2013, 2013. DOI: http://doi.org/10.1155/2013/132759

LEE, S. H.; JEONG, Y. S.; SONG, J.; HWANG, K. A.; NOH, G. M.; HWANG, I. G.. Phenolic acid, carotenoid composition, and antioxidant activity of bitter melon (Momordica charantia L.) at different maturation stages. International Journal of Food Properties, v.20, n.3, p.S3078-S3087, 2018. DOI: http://doi.org/10.1080/10942912.2016.1237961

LIMA, G. P. P.; VIANELLO, F.; CORRÊA, C. R.; CAMPOS, R. A S.; BORGUINI, M. G.. Polyphenols in fruits and vegetables and its effect on human health. Food and Nutrition Sciences, v.5, n.5, p.1065-1082, 2014. DOI: http://doi.org/10.4236/fns.2014.511117

LOBO, K. M. S.; ATHAYDE, A. C. R.; SILVA, A. M. A.; RODRIGUES, F. F. G.; LOBO, I. S.; BEZERRA, D. A. C.; COSTA, J. G. M.. Avaliação da atividade antibacteriana e prospecção fitoquímica de Solanum paniculatum Lam. e Operculina 
hamiltonii (G.. Don) D.F. Austin \& Staples do semi-árido paraibano. Revista Brasileira de Plantas Medicinais, v.12, n.2, p.227-233, 2010.

LøVDAL, T.; OLSEN, K. M.; SLIMESTAD, R.; VERHEUL, M.; LILLO, C.. Phytochemistry synergetic effects of nitrogen depletion, temperature, and light on the content of phenolic compounds and gene expression in leaves of tomato. Phytochemistry, v.71, n.5-6, p.605-613, 2010. DOI: http://dx.doi.org/10.1016/i.phytochem.2009.12.014

MARQUEZ, U. M. L.. O papel da clorofila na alimentação humana: uma revisão. Revista Brasileira de Ciencias Farmaceuticas, v.39, n.3, p.227-242, 2003. DOI: http://doi.org/10.1590/s1516-93322003000300003

OUERGHEMMI, I.; REBEY, I. B.; HARBAOUI, H.; HAMMAMI, M.; KSOURI, R.; TOUNSI, M.. Phenolic composition and antioxidant activity of Solanum sodomeaum fruit extract during two ripening stages. Jounal of New Sciences, v.46, n.3, p.2517-2526, 2017.

PELLEGRINI, N.; SERAFINI, M.; COLOMBI, B.; DEL RIO, D.; SALVATORE, S.; BIANCHI, M.; BRIGHENTI, F.. Total antioxidant capacity of plant foods, beverages and oils consumed in Italy assessed by three different in vitro assays. The Journal of Nutrition, v.133, n.9, p.2812-2819, 2003. DOI: http://doi.org/10.1093/jn/133.9.2812

RANIERI, G. R.. Guia prático sobre PANCs: plantas alimentícias não convencionais. São Paulo: Instituto Kairós, 2017.

RIOS, R.; SILVA, H.; CARNEIRO, N.; PIRES, A.; CARNEIRO, T.; COSTA, R.; MARQUES, C.; MACHADO, M.; VELOZO, E.; SILVA,
T.; CONCEIÇÃO, A.; ALCÂNTARA-NEVES, N.; FIGUEIREDO, C.. Solanum paniculatum $L$. decreases levels of inflammatory cytokines by reducing NFKB, TBET and GATA3 gene expression in vitro. Journal of Ethnopharmacology, v.209, p.32-40, 2017. DOI:

http://doi.org/10.1016/j.jep.2017.07.014

SILVA, M. B.; RODRIGUES, L. F.; ROSSI, T. C.; VIEIRA, M. C.; MINATEL, I. O.; LIMA, G. P. P.. Effects of boiling and oil or vinegar on pickled jurubeba (Solanum paniculatum L.) fruit. African Journal of Biotechnology, v.15, n.6, p.125-133, 2016. DOI: http://doi.org/10.5897/ajb2015.15077

SOUZA, A.; MOTA, L.; ZAMADEI, T.; MARTIM, C.; ALMEIDA, F.; PAULINO, J.. Classificação climática e balanço hídrico climatológico no estado de Mato Grosso. Nativa, v.01, n.01, p.34-43, 2013.

VALADARES, Y. M.; BRANDÃO, G. C.; KROON, E. G.; SOUZA FILHO, J. D.; OLIVEIRA, A. B.; BRAGA, F. C.. Antiviral activity of Solanum paniculatum extract and constituents. Zeitschrift fur Naturforschung - Section C Journal of Biosciences, v.64, n.11-12, p.813-818, 2010. DOI: http://doi.org/10.1515/znc2009-11-1210

VELA, S. M.; SANTOS, M. T.; SOUCCAR, C.; LIMA-LANDMAN, M. T. R.; LAPA, A. J.. Solanum paniculatum L.(Jurubeba): potent inhibitor of gastric acid secretion in mice. Phytomedicine, v.9, n.6, p.508-514, 2002

WILLIAMS, W. B.; CUVELIER, M. E.; BERSET, C.. Use of a free radical method to evaluate antioxidant activity. LWT - Food Science and Technology, v.28, n.1, p.25-30, 1995. DOI: http://doi.org/10.1016/S0023-6438(95)80008-5

A CBPC - Companhia Brasileira de Produção Científica (CNPJ: 11.221.422/0001-03) detém os direitos materiais desta publicação. Os direitos referem-se à publicação do trabalho em qualquer parte do mundo, incluindo os direitos às renovações, expansões e disseminações da contribuição, bem como outros direitos subsidiários. Todos os trabalhos publicados eletronicamente poderão posteriormente ser publicados em coletâneas impressas sob coordenação da Sustenere Publishing, da Companhia Brasileira de Produção Científica e seus parceiros autorizados. Os (as) autores (as) preservam os direitos autorais, mas não têm permissão para a publicação da contribuição em outro meio, impresso ou digital, em português ou em tradução. 